\title{
Rubén Darío y el Conde de Lautréamont
}

Darío menciona por vez primera a Lautréamont en un artículo que escribe para La Nación de Buenos Aires, fechado el 27 de noviembre de 1896, "Los colores del Estandarte", que encabeza con una cita del escritor montevideano:

La fin du dix-neuvième siècle vetra son poète (cependant, au début, il ne doit pas commencer par un chef-d'oeuvre, mais suivre la loi de la nature); il est né sur les rives américaines, à l'embouchure de la Plata, là où deux peuples, jadis rivaux, s'efforcent actuellement de se surpasser par le progrès matérial [matériel] et moral. Buenos Aires, la reine du Sud, en [et] Montevideo, la coquette, se tendent une main amie, à travers les eaux argentines du grand estuaire. ${ }^{1}$

Esta cita, utilizada por Darío como epígrafe de dicho artículo, corresponde al último párrafo del primer canto de Maldoror. El nicaragüense la utiliza para señalar un acierto del visionario Isidore Ducasse, quien había escrito esa profecía a fines de 1868 o principios de 1869. donde predecía la aparición de un gran poeta en la zona rioplatense. No sería extraño que el mismo Darío viese esa profecía realizada en su persona, que como genio poético, a pesar de haber nacido en Nicaragua, adquiere su plena madurez intelectual en la capital bonaerense.

En este artículo, especie de réplica a su maestro Groussac, que lo había criticado severamente a través de las páginas de La Biblioteca (Buenos Aires, XI, 1896), con motivo de la publicación de Los raros, Darío clarifica que no se trata de autores 'raros' que quiera presentar como modelos:

1 Isidore Ducasse, Oeuvres complètes (Paris: Le Livre de Poche, 1963), pp $90-91$. 
porque lo raro es lo contrario de lo normal, y después, porque los cánones del arte moderno no nos señalan más derroteros que el amor absoluto a la belleza clara, simbólica o arcana - y el desenvolvimiento y manifestación de la personalidad. Sé tu mismo: esa es la regla. ${ }^{2}$

Para Darío son "ratos" aquellos escritores disconformes con la realidad, tan diferentes entre sí como un Leconte de Lisle a causa de su aislamiento y de su augusta aristocracia. Rachilde y Lautréamont por ser únicos en la historia del pensamiento universal. Casos teratológicos, lo que se quiera, pero únicos, y muy tentadores para el psicólogo y para el poeta. Se trata pues de hombres sufridos, alejados del mundo o evadidos de él a través de paraísos artificiales, que buscan algo imposible de hallar. Ellos tienen como denominador común la sinceridad y el renunciar a la gloria efímera. Son seres amargados, atormentados por la genialidad y enfrentados en una lucha desigual con el público de su tiempo, que los señala como perversos y ridículos. Darío se refiere por tercera vez a Lautréamont en el mismo artículo, comparándolo a Whitman, a quien acaba de leer en su viaje a Buenos Aires, colocándolo también entre los raros, por su degeneramiento "raro, ratísimo, maestro de Maeterlinck". Whitman, nos dice, "rompió con todo y se remontó al versículo hebreo, se guió por su instinto". Y termina el artículo con las siguientes palabras dirigidas a Groussac, quien le enseñó a escribir cuando estuvo el nicaragüense en Buenos Aires:

Estamos, querido maestro, los poetas jóvenes de América de lengua castellana, preparando el camino, porque ha de venir nuestro Whitman, nuestro Walt Whitman indígena, lleno de mundo, saturado de universo, como el del norte, cantado tan bellamente por "nuestro" Martí. Y no sería extraño que apareciese en esta vasta cosmópolis, crisol de almas y razas, en donde vivió Andrade el de la Atlántida simbólica, y aparece este joven salvaje de Lugones, precursor quizá del anunciado por el enigmático y terrible loco Montevideano, en su libro profético y espantable. ${ }^{3}$

Darío publicó Los raros el 12 de octubre de 1896, en Buenos Aires, donde habla del montevideano en los siguientes términos:

2 E. Manes, Escritos inéditos de Rubén Dario (Nueva York: Instituto de las Españas, 1938), p. 123.

3 Ibid., p. 123. 
Vivió desventurado y murió loco. Escribió un libro que sería único si no existiesen las prosas de Rimbaud; un libro diabólico y extraño, burlón y aullante, cruel y penoso; un libro en que se oyen a un tiempo mismo los gemidos del Dolor y los siniestros cascabeles de la Locura.

León Bloy fue el verdadero descubridor del conde de Lautréamont. El furioso San Juan de Dios hizo ver como llenas de luz las llagas del alma del Job blasfermo. Mas hoy mismo, en Francia y Bélgica, fuera de un reducidísimo grupo de iniciados, nadie conoce ese poema que se llama Cantos de Maldoror, en el cual está va. ciada la pavorosa angustia del infeliz y sublime montevideano, cuya obra me tocó hacer conocer a América en Montevideo. ${ }^{4}$

Nosotros hemos seguido de inmediato la referencia de Bloy, dada por Darío, hasta encontrar en sus obras un artículo que nos ha ayudado a comprender esta relación literaria, entre dos poetas hispanoamericanos. Se trata de "Le cabanon de Prométhée (Sur Lautréamont)" publicado el 1 de septiembre de $1890 .^{5}$ Señalamos a continuación el fondo común de ambos artículos:

"Je rêvais, dit-il, que j'étais entré dans le corps d'un pourceau qu'il ne m'était pas facile d'en sortir, et que je vautrais mes poils dans les marécages les plux fangeux. Etait-ce comme une récompense? Objet de mes voeux, je n'appartenais plus à l'humanité! Pour moi, j'entendis l'interprétation ainsi, et j'en éprouvai une joie plus que profonde. Cependant, je recherchais activement quel acte de vertu j'avais accompli pour mériter, de la part de la Providence, cette insigne faveur...

"Mais, qui connaît ses besoins intimes ou la cause de ses joies pestilentielles?
"Soñé que había entrado en $A$ cuerpo de un puerco, que no me era fácil salir, y que enlodaba mis cerdas en los pantanos más fangosos. ¿Era ello una recompensa? Objeto de mis deseo: no pertenecía más a la humanidad! Así interpretaba yo, experimentando una más que profunda alegría. Sin embargo, rebuscaba activamente qué acto de virtud había realizado para merecer de parte de la Providencia este insigne favor...

"Mas ¿quién conoce sus necesid]des íntimas o la causa de sus goces pestilenciales?

4 Rubén Dario, Los raros (Madrid: Obras completas, Editorial Mundo Latino, 1920), p. 173.

5 La Plume, Paris, No 33 (septiembre 1, 1890), pp. 151-154. 
La métamorphose ne parut jamais à mes yeux que comme le haut et magnanime retentissement d'un bonheur parfait, que j'attendais depuis longtemps. Il était enfin venu, le jour où je fus un pourceau! J'essayais mes dents sur l'écorce des arbres; mon grain, je le contemplais avec délice! Il ne me restait plus la moindre parcelle de divinité: je sus élever mon âme jusq'à l'excessive hauteur de cette volupté ineffable..." (p. 51).

Le signe incontestable du grand poète, c'est l'inconscience plophétique, la troublante faculté do proférer pardessus les hommes et le temps, des paroles inouies dont il ignore lui-même la portée. Cela, c'est la mystérieuse estampille de l'Esprit-Saint sur des fronts sacrés ou profanes. Quelque ridicule qu'il puisse être, aujourd'hui, de découvrir un gran poète, inconnu et de le découvrir dans un hôspital de fous, je me vois forcé de déclarer, en conscience, que je suis certain d'en avoir fait la trouvaille ( $p$. 52).

"Je suis fils de l'homme et de la femme, d'après ce qu'on m'a dit. Cela m'étonne. Je croyais être davantage! (p. 53).

Ecoutez les chiens dans la nuit, ces terribles chiens homériques "aboyant tour à tour, soit comme un chat blessé au ventre au-dessus
La metamorfosis no pareció jamás a mis ojos sino como la alta $y$ magnífica repercusión de una felicidad perfecta que esperaba desde hacía largo tiempo. Por fin había llegado el día en que yo me convirtiese en un puerco! Ensayaba mis dientes sobre la corteza de los árboles; mi hocico, lo contemplaba con delicia. "No quedaba en mí la menor partícula de divinidad": supe elevar mi alma hasta la excesiva altura de esta voluptuosidad inefable." (p. 175)

$Y$ Bloy, "El signo incontestable del gran poeta es la "inconsciencia" profética, la turbadora facultad de proferir sobre los hombres y el tiempo palabras inauditas cuyo contenido ignora él mismo. Esa es la misteriosa estampilla del Espíritu Santo sobre las frentes sagradas $u$ profanas. Por ridículo que pueda ser, hoy, descubrir un gran poeta y descubrirle en una casa de locos, debo aclarar en conciencia que estoy cierto de haber realizado cl hallazgo" (p. 178).

Lautréamont: "Soy hijo del hombre y de la mujer, según lo que se me ha dicho. Creía ser más" (p. 174).

Oid la voz macabra del raro visionario. Se refiere a los perros nocturnos, en este pequeño poema en prosa, que hace daḱo a los ner- 
d'un toit, soit comme un enfant qui crie de faim, soit comme un chat blessé au ventre au-dessus d'un toit, soit comme une femme qui va enfanter, soit comme un moribond atteint de la peste à l'hôspital, soit comme une jeune fille qui chante un air sublime; contre les étoiles au nord, contre les étoiles à l'ouest; contre la lune; contre les montagnes, semblables au loin à des roches géantes, gisantes dans l'obscurité; contre l'air froid qu'ils aspirent à pleins poumons, qui rend l'intérieur de leur narines rouge et brûlant; contre le silence de la nuit; contre les chonettes dont le vol oblique leur rase le museau, emportant un rat ou une grenouille dans le bec, nourriture vivante, douce pour les petits; -contre les lièvres qui disparaissent en un clin d'oeil; contre le voleur, qui s'enfuit, au galop de son cheval, aprés avoir commis un crime; contre les serpents, remuant los bruyères, qui leur font trembler la peau, grinces des dents-; contre leur propres aboiements, qui leur font peur à eux-mêmes; contre les crapauds, qu'ils broient d'un coup sec de mâchoires (porquoi se sont-ils éloignés du marais?); contre les arbres, dont les feuilles, mollement barcées, sont autant de mystères qu'ils ne comprennent pas, qu'ils veulent découvrir avec leurs yeux fixes, intelligents; -contre les araignées suspendues entre leurs longues pattes, qui grim- vios. Los perros aúllan "sea como un niño que grita de hambre; sea como un gato herido en el vientre, bajo un techo; sea como una mujer que pare; sea como un moribundo atacado de la peste, en el hospital; sea como un joven que canta un aire sublime - contra las estrellas al Norte, contra las estrellas al Oeste, contra la luna; contra las montañas, semejantes, a lo lejos, a rocas gigantes, yacentes en la obscuridad; - contra el aire frío que ellos aspiran a plenos pulmones, que vuelve lo interior de sus narices rojo y quemante; contra el silencio de la noche; contra las lechuzas, cuyo vuelo oblicuo les roza los labios y las narices, y que llevan un ratón o una rana en el pico, alimento vivo, dulce para la cría; contra las liebres, que desaparecen en un parpadear; contra el ladrón que huye, al galope de su caballo, después de haber cometido un crimen; contra las serpientes agitadoras de hierbas, que les ponen temblor en sus pellejos y les hacen chocar los dientes; - contra sus propios ladridos, que a ellos mismos dan miedo; contra los sa. pos a los que revientan de un solo apretón de mandíbulas (¿para qué se alejaron del charco?); contra los árboles, cuyas hojas, muellemente mecidas, son otros tantos misterios que no comprenden, y quieren descubrir con sus ojos fijos inteligentes; -contra las arañas suspendidas entre las largas patas, 
pent sur les arbres pour se sauver; contre les corbeaux, qui n'ont pas trouvé de quoi manger pendant $\mathrm{k}$ journée, et qui s'en reviennent au gite, l'aile fatiguée; contre les ro. chers du rivage; contre les feux, qui paraissent aux mâts des navires invisibles; contre le bruit sourd des vagues; contre les grands poissons qui, nageant, montrent leur dos noir, puis s'enfoncent dans l'abîme; et contre l'homme qui les rend esclaves!...

"Un jour, avec des yeux vitreux, ma mère me dit: "Lorsque tu seras dans ton lit, que tu entendras les aboiements des chiens dans la campagne, cache-toi sous ta couverture, ne tourne pas en dérision ce qu'ils front: ils ont une soif insatiable de l'infini, comme moi, comme le reste des humains, à la figure pâle et longue"... Moi, comme les chiens, j'éprouve le besoin de l'infini... Je ne puis contenter ce besoin!" (p. 53-54).

Je soupçonne cet infortuné de n'avoir été qu'un blasphémateur par amour, exactement, je le suppose, comme il devint un insensé. Après tout, cette haine enragée du Créateur, de l'Eternel, du Tout-Puissant, ainsi qu'il s'exprime, est assez vague dans son objet, puisqu'il ne touche jamais aux Symboles (p. 55). que suben a los árboles para salvarse; contra los cuervos que no han encontrado qué comer durante el día y que vuelven al nido, el ala fatigada; contra las rocas de Ja ribera; contra los fuegos que fingen mástiles de navios invisibles; contra el ruido sordo de las olas; contra los grandes peces que nadan mostrando su negro lomo y se hunden en el abismo, - $y$ contra el hombre que les esclaviza...

"Un día, con ojos vidriosos, me dijo mi madre: - Cuando estés en tu lecho, y oigas los aullidos de los perros en la campaña, ocúltate en tus sábanas, no rías de lo que ellos hacen; ellos tienen una sed insaciable de lo infinito, como yo, como el resto de los humanos, a 1a "figure pâle et longue..." "Yo -sigue él一, como los perros, sufro la necesidad de lo infinito. No puedo, no puedo llenar esa necesidad." (p. 175-176).

León Bloy, que en asuntos teológicos tiene la ciencia de un doctor, explica y excuse en parte la tendencia blasfematoria del lủgubre alienado, suponiendo que no fue sino un blasfemo por amor. "Después de todo, este odio rabioso para el Creador, para el Eterno, para el Todopoderoso, tal como se expresa, es demasiado vago en su objeto, puesto que no toca nunca los Símbolos", dice (p. 175). 
La Prostitution sous toutes ses formes est une idée fixe qui escorte habituellement, dans son livre, l'idée du Seigneur, comme un corollaire suit un axiome.

"J'ai fait un pacte avec la prostitution, afin de semer la désordre dans les families... Hélas! hélas! s'écria la belle femme nue, les hommes, un jour, me rendront jus. tice; je ne t'en dis pas davantage. Laisse-moi partir pour aller cacher au fond de la mer ma tristesse in. finie. Il n'y a que toi et les monstres hídeux qui grouillent dans ces noirs abîmes qui ne me méprisent pas" (p. 56).

"-Le gran-duc de Virginie, bean comme un mémoire sur la courbe que décrit un chien en courant aptès son maître..... Le vautour des agneaux, beau comme la loi de l'arrêt de développement de la poitrine chez les adultes dont la propension à la croissance n'est pas en rapport avec la quantité de molécules que leur organisme s'assimile... Le scarabée, beau comme le tremblement des mains dans l'alcoolisme... L'adolescent, beau comme la rétractilité des serres des oiseaux rapaces; ou encose comme l'incertitude des mouvements musculaires dans les plaies des parties molles de la région cetvicale postérieure; ou plutôt comme ce piège à rats perpétuel, toujours retendu par l'animal pris, qui peut prendre seul des rongeurs indéfi-
La Prostitución es para él el misterioso símbolo apocalíptico, entrevisto por excepcionales espírttus en su verdadera trascendencia.

"Yo he hecho un pacto con la Prostitución, a fin de sembrar el desorden en las familias... -ay! ay! grita la bella mujer desnuda: los hombres algún día serán justos. No digo más. Déjame partir. para ir a ocultar en el fondo del mar mi tristeza infinita. No hay sino tú y los monstruos odiosos que bullen en esos negros abis. mos, que no me desprecien." ( $p$. 178).

"...El gran duque de Virginia era bello, bello como una memoria sobre la curva que describe un perro que corre tras de su amo ..." El vautour des agneaux, bello como la ley de la detención del desarrollo del pecho en los adultos cuya propensión al crecimiento no está en relación con la cantidad de moléculas que su organismo se asimila... El escarabajo, "bello como el temblor de las manos en el alcoholismo... "El adolescente, "bello como la retractilidad de las garras de las aves de rapiña" o aun "como la poca seguridad de los movimientos musculares en las llagas de las partes blandas de región cervical posterior", o, todavía, "como esa trampa perpetua para ratones, "toujours retendu par l'animal pris, 
niment et fonctionner même caché sous la paille, et surtout, comme la recontre fortuite sur une table de dissection d'une machine à coudre et d'un parapluie..." (p. 58).

"-Adieu, vieillard, et pense à moi si tu m'as lu. Toi, jeune homme, ne te désespère point; car tu as un ami dans le vampire, malgré ton opinion contraire. En comptant l'acarus sarcopte qui produit la gale, tu auras deux amis". qui peut prendre seul des rongeurs indéfiniment, et fonctionner même caché sous la paille', y sobre todo, bello "como el encuentro fortuito, sobre una mesa de disección, de una máquina de coser y un $\mathrm{p}$ raguas..." (p. 177).

"Adieu vieillard, et pense à moi, si tu m'as lu. Toi, jeune homme, ne te désespère point; car tu as un ami dans le vampire, malgré ton opinion contraire. En comptant l'acarus sarcopte qui produit la gale, tu auras deux amis". ${ }^{\circ}$

Al final de su artículo sobre Lautréamont, León Bloy habla de Satanás, relacionándolo con una flora diabólica que deambula en los Cantos. Dario tomará la misma idea de Bloy, colocándola también al final de su artículo sin traducirla literalmente:

Il succomba, comme Satan, pour Ser sublime martirizado por Saavoir "Vaincu l'Espérance" (p. tanás... El Bajísimo le poseyó 59). (p. 177).

Dans l'espoir de fuir, son imagination éperdue le précipite aux métamorphoses. Il se rappelle "avoir vécu un demi-siècle, sous la forme de requin..."; il se reconnaît un visage d'hyène; il a de longs entretiens avec "le frère de la sangsue" et "le poulpe au regard de soie"... (p. 59-60).

En las seis partes de su obra, sembró una flora enferma, leprosa, envenenada. Sus animales son aquellos que hacen pensar en las creaciones del Diablo: el sapo, el buho, la víbora, la araña. La desesperación es el vino que le embriaga (p. 178).

Darío, siguiendo a Bloy, habla también del poco conocimiento que se tiene de la vida y obra de Lautréamont:

"L'un des signes les moins dou- El poema de Lautréamont se puteux de cet acculement des âmes blicó hace diez y siete años en Bél-

6 Rubén Darío, "El Conde de Lautréamont", Los raros, pp. 173-178. 
modernes à l'extrémité de tour, gica. De la vida de su autor nada c'est la récente intrusion en Fran- se sabe. Los "modernos" grandes ce d'un monstre de livre, presque artistas de la lengua francesa se inconnu encore quoique publié eis hablan del libro como de un devoBelgique depuis dix ans: les cionario simbólico, raro, inenconChants de Maldoror, par le comte trable (p. 178).

de Lautréamont, ouvre tout à fait sans analogue et probablement ap. pelé à retenir. L'auteur est mơt dans un cabanon et c'est tout ce qu'on sait de lui (p. 48).

Tampoco es de Darío la opinión del desequilibrio mental del montevideano, ya citado por León Bloy desde enero de 1887 en su libro Le Désespéré, cuando menciona por vez primera el nombre de Lautréamont en Francia. En su artículo ya mencionado de La Plume (1890), León Bioy se refiere a Lautréamont como "aliené" (p. 49), "dément" (p. 52); "maniaque" (p. 55), "frappé de folie" (p. 56), "insensé" (p. 57), "fou" (p. 59). En 1896 Darío utilizará estos mismos calificativos al referirse al escritor uruguayo: "loco" (p. 173, 174, 176), "locura" (p. 173-174-175), "alienado" (p. 175). "Se trata de un loco, ciertamente" (p. 176) equivalente a "ça, c'est un vrai fou, hélas!" (p. 59).

León Bloy usa el calificativo de "blasphème" tres veces (p. 50, 51, 55) y Darío dos veces (p. 173, 175). El escritor francés cita dos veces la palabra matemáticas para referirse a Lautuéamont, "mathématicien" (p. 56), "mathématiques" (p. 57) y Dario una vez "atracción de las matemáticas". Bloy habla de "chiffres cabalistiques" (p. 57) y Darío del "consejo de la Kabala" (p. 174). Bloy hablará del montevideano que no cesa "de vociférer son désespoir que pour sibiler sa douleur?" (p. 59) y Darío nos dirá "Si yo llevase a mi musa cerca del lugar en donde el loco está enjaulado vociferando al viento" ( $p$. 174).

Hay otros juicios que se repiten en ambos artículos: León Bloy nos habla de este libro "presque inconnu encore quoique publié en Belgique depuis dix ans" y Darío "El poema de Lautréamont se publicó hace diecisiete años en Bélgica" (p. 178); "l'auteur est mort dans un cabanon et c'est tout ce qu'on sait de lui" (p. 48) y Darío: "De la vida de su autor nada se sabe". (p. 178). Bloy menciona a Baudelaire, "les sataniques litanies des Fleurs du Mal" (p. 48) y Dario hace refe- 
rencia también al poeta maldito "Es un agradable cumplimiento para el lector el que Baudelaire le dedica en las Flores del Mal"' (p. 177).

Hay, inclusive, pasajes que Darío cita directamente en francés: "Le vautour des agneaux", (p. 177) y las líneas finales del artículo de Bloy que reproduce Darío "Adieu vieillard, et pense à moi..." (p. 177).

Este cotejo nos permite ver la semejanza de ambos artículos, o mejor, la casi total reproducción que Dario hace en Los raros del estudio de León Bloy sobre Lautréamont.

En un artículo dedicado a Lugones "Lo que encontré en las Mon tañas del Oro" (El Tiempo: Buenos Aires 26 de noviembre de 1897), Darío vuelve a referirse a Lautréamont:

Oh Beluario! magnifico y querido, blando como un infante real, peligroso como una flecha, potente como una catapulta. Pláceme ver en ti el Montevideano en su Cabanon presumió: [sic] pláceme ver en ti el milagroso cetro del poeta nuevo.?

Darío menciona de nuevo a Lautréamont, en una conversación que sostuvo con Alejandro Sux, en París. Hablaban de Alfredo de Musset, el poeta más amado de los franceses, el que más monumentos tiene en la capital francesa, cuya tumba visitó y pudo ver allí el sauce traído por el Montevideano ante la conocida súplica que hizo el poeta francés a sus amigos:
Mes chers amis, Quand je mourrai Plantez un saule au cimetière...8

Darío, nos cuenta Alejandro de Sux, se maravillaba entonces de la atmósfera cultural francesa, al comentar el siguiente incidente:

En cierta ocasión halló en un banco del Jardín de Luxemburgo a un carnicero leyendo versos de Alfredo de Musset. Me contó el incidente con pelos y señales... Darío tomó asiento junto a él y conversó de Musset. El carnicero sabía los versos y la vida del poeta de "Les nuits". Darío se emocionó cuando el lector, a quien había dicho que conocía Buenos Aires y Montevideo, le reveló

7 Mapes, op. cit., p. 130.

- Ismael López (Cornelio Hispano), De París al Amazonas (París: Libretía Paul Ollendorf, sin fecha), p. 27. 
que un uruguayo, el poeta Lautréamont, había traído del Río de la Plata un sauce llorón que plantó en la tumba de Musset. ${ }^{2}$

Cuando el poeta nicaragüense se encontraba enfermo en Guatemala, bajo la protección del tirano Estrada Cabrera, quien le proporcionaba toda clase de licores a cambio de encomios del poeta moribundo, un escritor guatemalteco lo visita a fines de 1915. Arévalo Martínez pide al poeta ebrio que le dé una opinión sobre su reciente obra, El bombre que parecia un caballo, y entonces Dario lo compara con el montevideano. Reproducimos parte de esta entrevista:

Hoy, en mis temporadas de embriaguez, bebo una copa cada cinco minutos; pero habla, porque me encuentro lúcido.

Fui a hablar. El Maestro me impuso silencio con un ademán lleno de majestad.

- ¿Crees, preguntó, con imponente voz, crees en mí?

- Sí, Maestro, le dije: creo.

-Entonces, apunta este nombre que voy a pronunciar:

Lautréamont. El conde de Lautréamont. $\mathrm{Y}$ apunta este otro nombre, que es el de su única obra, Los Cantos de Maldoror. Lautréamont es el único poeta, y su obra es la única obra, que dan, aunque sea con vaguedad, un precedente a tu extraña obra. En mi libro Los Raros encontrarás algunas noticias sobre él. Tu obra, fucra del caso único del terrible Conde, no tiene igualdades ni analogías ni precedencias. ¿Qué minas nuevas, en subsuelos desconocidos, entraste a explotar? ¿Qué filones no sospechados sacaste? Dejé al gran poeta y al marchar por las calles iba conturbado. En la primera librería que encontré al paso compré un ejemplar de Lou Raros y leí las páginas destinadas a Lautréamont. ¡Oh, horror? Lautréamont era un loco, Lautréamont había sido un poeta demente y blasfemo, que murió en un hospital de Montevideo. Asustado acudi, al día siguiente, de nuevo, donde el gran Maestro.

-Señor, le dije, he leído sus páginas sobre Lautréamont; pero Lautréamont era un loco. Entonces ¿usted cree que yo también estoy loco?

-Sí, me contestó, loco, loco completamente loco. Loco como yo mismo. Loco como Nerval y como Poe. ${ }^{10}$

"Alejandro Sux, "Rubén Datío visto por Alejandro Sux", Revista Hispánica Moderna (Nueva York, XII, 1946), p. 316.

10 Rafael Arévalo Martinez, "Seis anécdotas de Rubén Dario", Boletin de la Biblioteca Notcional (Guatemala, 1934), pp. 399-400. 
En la época de Los raros, Darío no sólo había leído el artículo publicado por León Bloy, en La Plume, sino también otros estudios como el de Remy de Gourmont "La littérature Maldoror" (Mercure de France, II, no. 14, 1891, pp. 97-106) y seguramente había leído también del mismo autor Le livre des masques, que apareció por vez primera en 1896. Remy de Gourmont ya había comparado al montevideano con Poe al comentar la literatura Maldoror, ${ }^{11}$ y Dario parece que tomara de él esta idea cuando dice:

Con quien tiene puntos de contacto es con Edgar Poe. Ambos tuvieron la visión de lo extranatural, ambos fueron perseguidos por los terribles espíritus enemigos... ambos experimentaton la atracción de las matemáticas, que son, con la teologia y la poesía, los tres lados por donde puede ascenderse a lo infinito. Mas Poe fue celeste, y Lautréamont infernal. ${ }^{12}$

Genonceaux publicó una edición de Les Chants de Moldoror, con una carta escrita con la letra de Ducasse y un prólogo, en 1890. Se trataba de una edición de lujo muy restringida, "entreprise avec le désintéressement d'un plaisir personnel", que dudamos haya leído Rubén Darío. ${ }^{13}$

¿Por qué incluyó a Lautréamont en Los raros? 1. Porque se trataba de un verdadero "raro" de la época; 2. por ser un poeta latinoamericano; 3. por admirar ambos al norteamericano Edgar Allan Poe, cuya chra habian leído en su juventud; porque ambos vivieron en calidad de extranjeros, lejos de su patria, segregados, nostálgicos. Un crítico nos dice refiriéndose a Darío:

En determinados momentos de su vida, por su melancolía y su ingenuidad a lo Verlaine, es un alma en ruinas semejante al Conde de Lautréamont; ${ }^{14}$

11 Remy de Gourmont, Le livre de masques (París: Mercure de France, 1963). Este autor comenta también Las poesías de Lauttéamont, no mencionadas por Dario, en "La Litterature Maldoror", Mercure de France, II, No 14 (1891), pp. 97-106.

12 Los raros, pp. 174-175.

1.3 Remy de Gourmont, op. cit., pp. 83-88. El Second ?inre de masques se publicó en 1898.

14 Roxana Gardes, "Lo raro en 'Los Raros'", Rubén Dario (Estudios reunidos en conmemoración del centenario: 1867-1967) (Buenos Aires: Universidad Na. cional de La Plata, 1968), p. 192. 
Podemos agregar que los dos vates latinoamericanos crecieron sin el amor maternal; ambos eran tristes $y$ silenciosos; en ambos hay temor de la muerte; los dos sufrieron necesidades económicas (recuérdese 'la Profecía de Horacio' de Darío, y el dinero que tuvo que poner de su bolsillo Ducasse para publicar Los Cantos de Maldoror):

lettres ayant toutes trait à des questions économiques. Rapport économique au père, rapport économique à la société, seule réa. lité biographique qu'enfin notre auteur reconnaît. ${ }^{15}$

Tanto Darío como Lautréamont habían devorado durante su ado. Iescencia muchos libros, fucron grandes lectores: "son imagination est environnée de livres", dice Maurice Blanchot refiriéndose a Ducasse. $E$ inclusive muchas de las fuentes literarias de ambos autores coinciden: el Apocalipsis, Byron, Milton, Alfredo de Musset, Shakespeare, Dante, Baudelaire, etc. ${ }^{16}$

La música influye también en ambos autores: Lautréamont ha sido clasificado como "sonore et symphonique à la manière de Berlioz"17 y a la obra poética de Darío la ha calificado Anderson Imbert como una "orquesta sinfónica".18

Como conclusiones, podemos sacar las siguientes:

1. Es muy probable que Darío no había leído la obra de Lautréamont, cuando le dedicó un artículo en Los raros, en 1896.

2. El conocimiento de Lautréamont provenía, casi en su totalidad, de un artículo publicado por León Bloy en La Plume (septiembre 1, 1890), cuyo título era "Le cabanon de Prométhée".

3. Dario reproduce las tres cuartas partes de dicho artículo, e inclusive emplea el mismo vocabulario de León Bloy: "loco", "demente", "alienado", "blasfemo", etc.

4. Cuando Darío publicó Los raros (1896), no se dio cuenta de la aparición de un nuevo lenguaje en la obra de Lautréamont. ${ }^{19}$ Sin em-

15 Marcelin Pleynet, Lautréamont par luitmême (Paris: Collections Microcosme, Ecrivains de Toujours, 1967), p. 49.

16 Maurice Blanchot, Lautréamont et Sade (Paris: Union Générale d'Editions, 1963), nos dice "Lautréamont est sans doute un adolescent cultivé. Il a lu avec passion toutes les reuvres que la vie du temps rend grandes et fascinantes", pp. 105-97. Véase también la obra de Plevret, p. 98.

17 Gaston Bachelard, Lautréamont (Paris: Librairie Jose Corti, 1965), p. 87.

18 Entique Anderson-Imbert, Crifica interna (Madrid: Taurus, 1960), p. 207.

19 José Angel Valente dice "La irradiación de Lautréamont en el ámbito peninsular ha de buscarse a favor de la apatición de un nuevo lenguaje al ous el superrealismo no es ajeno. Desde este punto de vista, la inclusión de Lautréamont en Las faros de Rubén Darío, carece necesariamente de significación pro- 
bargo, al final de su vida, Darío ve en este autor una gran originalidad: "no tiene igualdades, ni analogías ni precedencias". ¿Qué minas nuevas, en subsuelos desconocidos, entraste a explotar? ¿Qué filones no sospechados sacaste? "le dice a su amigo guatemalteco Rafael Arévalo Martínez.

5. Darío se muestra como divulgador de las figuras literarias de su tiempo, en América. Al hablar del montevideano declara "cuya obra me tocó hacer conocer a América en Montevideo". En efecto, su artículo aparecido en La Nación influyó considerablemente a autores como Leopoldo Lugones, Julio Herrera y Reissig y Ricardo Güiraldes, quienes leyeron más tarde a Lautréamont y cuyas huellas podemos rastrear en sus escritos.

6. Darío escogió a este autor en Los raros quizá por la marcadd semejanza que le ofrecía al comparar su vida con la del poeta montevideano: ambos nacidos en América, huérfanos desde muy niños, levantados bajo el cuidado de terceras personas, nostálgicos en Europa, tristes y ensimismados sentían un horrible temor de la muerte. Ambos admiraban a Poe, sufrieron toda clase de necesidades económicas y fueron incomprendidos en su época. ${ }^{20}$

$Y$ en cuanto a la obra de estos dos creadores, se caracterizan por el ritmo musical y sonoro, y por haber sido ambas influidas por libres como la Biblia y autores como Byron, Shakespeare, Poe, Milton, Dante, Alfredo de Musset, Baudelaire, etc. ${ }^{21}$

funda", en "Tres notas sobre Lautréamont", Insula (Madrid: XXV, No 282, mayo 1970), pp. 1-10.

20 Fsta relación literaria Lautréamont-Darío no ha sido mencionada en el libro de E. Mapes, L'influence françatise dans l'oeuvre de Rubén Dario (Paris: Libraitie Ancienne Honoté Champion, 1925), ni en el de Anderson-Imbert, La originalidad do Rubén Dario (Buenos Aires: Centro Editor de la América Latina, Biblioteca de Literatura, 1967).

21 Al terminar este artículo, hemos encontrado nuevos datos relacionados con este tema, en "Noticias de Lautréamont y Laforgue", dadas por Dario y que transcribimos a continuación:

Antes de partir para América, en mi reciente viaje, recibí una carta de $\mathrm{M}$. de Gourmont en que me decía: "Isidore Ducasse (éste es el verdadero nombre de Lautréamont) est né á Montevideo, le 4 abtil 1846, a $4 \mathrm{~h}$. du matin. C'est ce que porte son extrait de naissance qui m'a été envoyé par le consulat de France á Montevideo; et que j'ai publié dans le "Mercute" de France de nov. 91, ou tome III de la colección, p. 318.

"Puis qui vous allez á Montevideo, demandes a voir le registre même. et verifie bien le nom d'un térmoins qu'on a transcrit, Laforgue, et qui pourrait bien etre Laforgue Curieux, si le pére de Laforgue avait été l'un de ceux qui déclatérent la naissance de Lautréamont."

Durante mi permanencia en Montevideo no me fue posible averiguar lo que hubiese al respecto. Yo ruego a mis amigos de Montevideo quieran 
¿Cuándo se tradujo por primera vez Laturéamont al castellano? Mucho antes de que los surrealistas lo convirtieran en un dios máximo de la poesía. En 1909, la revista Promelec, fundada por Javier Gómez de la Serna y dirigida luego por su hijo Ramón, publicó unas páginas de los Cantos, en versión de Ricardo Baeza. Pero la primera traducción castellana completa de Los Cantos de Maldoror no aparece hasta 1927, editada por Biblioteca Nueva, y es obra de Julio Gómez de la Serna.?

Publio GonzÁlez-RodAs

\section{Université de Montréal}

tomarse el trabajo de enviarme todos los datos que puedan obtener sobre las familias de Laforgue y de Ducasse, y de examinar la firma, a que se refiere mi amigo M. de Gourmont, en el consulado de Francia. Agradeceré mucho cualquier noticia que se me dirija a mi domicilo en París, 133 Rue Michel Angel (Pedto Luis Barcia, Escritos dispersos de Rubén Darío, recogidos de periódicos de Buenos Aires) (Buenos Aires: Universidad Nacional de la Plata, 1968), pp. 290-291.

22 José Luis Cano, "Lautréamont entrevisto", Cultura Universitaria (Caracas, No 89, octubre-diciembre 1965), pp. 91-97. Melchor Fernández Almagro dedica unas páginas a "Rubén Darío y Lautréamont" en su libro, En torno al 98 (Politica y Litieratura) (Madrid: Editorial Jordán, 1948), pp. 151-153. 
